\title{
A Study on the Mode of Data Structure by Micro Learning Based on Smart Phones
}

\author{
Xiaoming Yang \\ College of engineering and technology, Xi'an Fanyi University Xi'an 710105 \\ 26254588@qq.com
}

Keywords: Micro learning; Smart phones; Data structure

\begin{abstract}
With the rapid development of mobile communication technology and the growing popularization of smart phones, micro learning is a brand-new learning method under the change of lifestyle and the coming of MicroAge. In this paper, we will apply this learning method on Data Structure and design a model in this course by Micro Learning based on smart phones.
\end{abstract}

\section{Introduction}

The development of Internet and mobile communication technologies has promotednew media technologies, and led to major changes in people's learning environment and learning methods. At the same time, it also reformed the education and learning styles. With its short content, diverse forms, flexible time and place, Micro Learning is more and more popular among people, and has become a hot spot that experts and scholars generally pay attention to and study.

Present Situation on the study of Micro Learning. Lindner, an Austrian scholar, first came up with the concept of Micro Learning in 2004 and supposed that Micro Learning, as a new type of learning, existed in the life system of new media and played an importantrole on the basis of theory which opened up new learning ideas in the mobile technology and smart phone era based on micro-content and micro-media. After that, Silvia Gabrielli, Martin Lindner and Theo Hug gave different explanations of micro-learning from different aspects such as media, content and time respectively, so that Micro Learning can be rapidly carried out and studied abroad [1-3].

In 2008, Domestic scholars also initiated the research on the Micro Learning. Domestic research placed more emphasis on the application of Micro Learning, from the understanding of Micro Learning to the micro-classes in primary and middle schools and to the reform of English courses in colleges and universities. There are some representative examples such as "micro-study: the present situation and the future" published by ZHANG Zhen-hong in 2013 [4];"The Study of primary and secondary schools' Micro-course" published by Tang Jun; "the Application of Micro Learning in Colleges and Universities" published by WU Jin-hong in 2014. In 2017 [5], Zhang Chunchao applied Micro Learning to non-English majors in higher vocational colleges [6]. The results showed that it improved their listening and oral English. Li Jing put micro-study of postgraduates' English classes into practice and made "Inverted Classroom" come true. Obviously, Micro Learning in China is very popular in recent years. Its research values, especially in the field of applied teaching, has provided new ideas and new methods in teaching reform and achieved good results [7-8].

Problems on the Teaching Process of Data Structure. Data structure is a very comprehensive course, which requires students to understand and master discrete mathematics, computer language and other fields of knowledge, especially to have a good computer language skills, computer science The students who are poor at Computer Language will have difficulty in learning this course. Compared with other applied courses, the contents are abstract and boring, so that teachers are also hard to pass on.

Therefore, how to reduce the degree of theory, enhance intuitiveness and improve students' interest in learning is a very important issue for teachers. Teachers should actively study the characteristics of the curriculum system, innovate and adopt appropriate teaching methods by exchanging boring and difficult algorithm vividly, and then cultivate students' ability of autonomous learning. From specific examples, teachers should arrange the practices to improve the hands-on 
ability of students. In teaching process, we should not only vividly and exhaustively explain knowledge, but lead the students to think over; we should not only require the students to listen carefully, but also guide the students to think actively and gradually develop the students' abilities to find, analyze and solve problems.

\section{The Meaning of Applying Micro Learning on Data Structure}

In the one hand, as university lifestyles have changed, students' fragmented time will be increased. There are a large amount of fragmented time in the classrooms, playgrounds, restaurants and other places. Smart Phones can take advantage of this phenomenon. Although the faculty of colleges and universities have already strictly controlled, why not use this opportunity if they were used fragmented time properly to improve their academic performance? In the other hand, Data Structure has a theoretically strong sense and the algorithm is relatively abstract and difficult to understand. In traditional classes, we are used to having the aid of multimedia courseware, small media classrooms and computer aided software to enhance the effect of teaching process. However, teaching alone can not fully grasp and digest the teaching content. Therefore, applying the new learning mode of Micro Learning to this course in colleges and universities can strengthen the apply of Micro Learning and enable innovations for this course.

Mobile micro-learning, as a good extension and complement of classroom learning, will extent teaching time and space. In the mode of micro-learning teaching, teachers can make micro-knowledge units which includes key points, difficult points, extended contents, after-class exercises and chapter tests into micro-resources. Students can learn this course anytime, anywhere after class with the help of mini-media devices such as Smart Phones. In addition, the network features of miniature media devices can make communication among people more convenient, and teachers and students can easily discuss the lessons and knowledge even outside the classroom.

Therefore, with the introduction of data structure by Micro Learning teaching, students can effectively use their smart phones and spare time to digest the classroom content in-depth learning. Furthermore, Micro Learning will be brought flexibility and new learning experience and developed students' ability to learn independently.

\section{A Study on the Mode of Data Structure by Micro Learning}

The Characteristics of Data Structure by Micro Learning. Compared with the traditional teaching mode, using the Micro Learning can make time and place become flexible and free, and it is suitable for students to learn this course independently. College students have colorful activities, make friends, participate in school associations and social practice, so they have much more fragmented time to use. If we provide a simple and understandable knowledge or algorithm demonstration on the developed Micro Learning platform, and present some abstract and difficult-to-understand knowledge in a dynamic way. It will not only be able to arouse students' interest and quickly understand what they have learned, but also to develop their awareness of self-learning, so that students can gain a sense of fulfillment and self-achievement.

In addition, micro-learning can take the needs of each student into consideration. According to ability to students, we can design develop different levels from easy to difficult, even extensive knowledge. Display can also be varied to different types which can be satisfied with students' styles on the text, images, audio, video, etc., so that students will have opportunities to choose one of the most favorite learning ways. It will not only meet the cognitive rules of individualized learning, but also stimulate students desire for more knowledge[9-10].

The Development of Curriculum Resource. How can we achieve the development of curriculum resource? We should mainly exchange the systematic resources to fragmented resources, static resources to dynamic resource, long-time and boring content to flexible learning micro-curriculum. And each micro-curriculum can no be separated, but there is a hidden relationship between the system. We should establish a systematic knowledge system for the micro-class, find the contacts of the knowledge network and open up the path of communication 
for knowledge.

According to the teaching purposes and requirements, we can design micro curriculum with the mode of "key points, difficult points, Q \& A discussion". Teachers can divide the whole course into different subjects to show the micro-curriculum topics and highlights. Students can start from a certain point of knowledge and select one micro-chip content on purpose. Students can take advantage of their fragmented time for autonomous learning to make complement and expansion even after class. Here is an example about linear list from Data Structure. Teachers divide the teaching process into multiple microknowledge points, and the connection between the microknowledge points is as shown in Fig1.

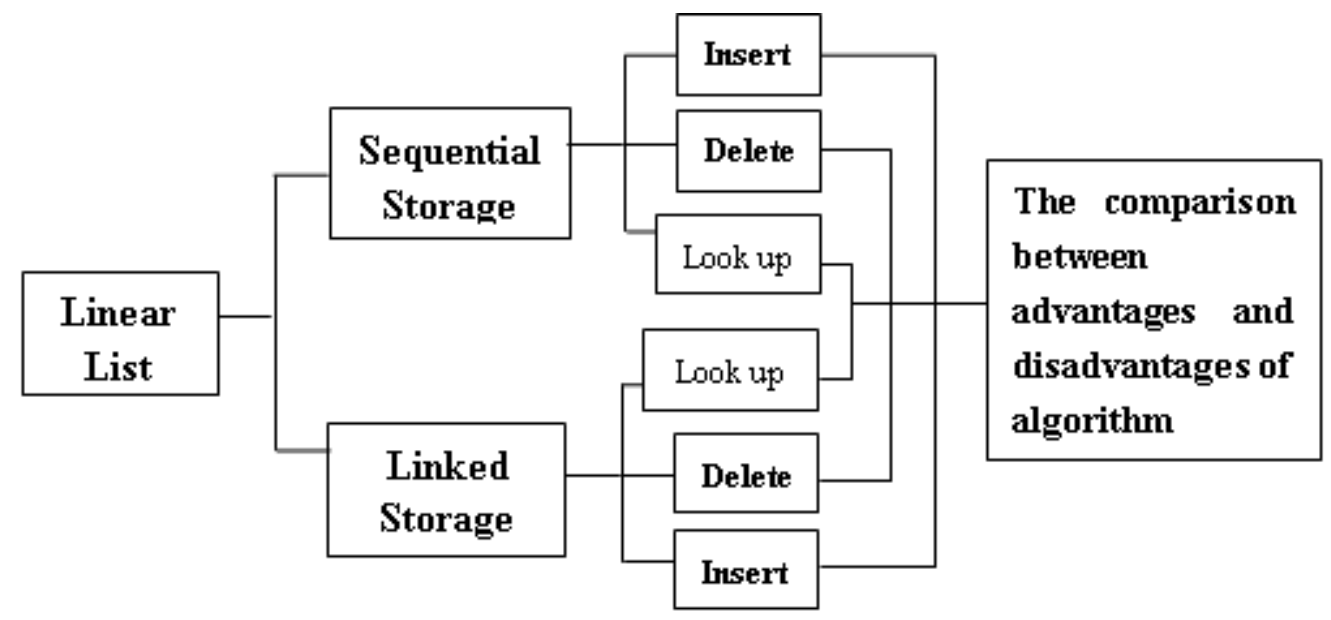

Figure 1. Division of Micro Knowledge point

The Construction of Data Structure by Micro Learning. The goal of this micro-curriculum is to utilize the student's fragmented time to provide students with thematic and fragmented learning resources and to carry out the teaching process through smart phone. According to their teaching methods, micro-curriculum can be divided into lecture class, demonstration class, discussion class, practice class, autonomous learning class and cooperative learning class, which are based on the interaction between after-class autonomous learning and in-class teaching.

The construction of data structure by Micro Learning is divided into two parts: teacher's end and student's end. The teacher's end is divided into four stages according to knowledge, pre-class design, teaching process, after-class evaluation. As for students, there are also four stages: preview, learning content, class interaction and after-class discussion. The four stages require students to complete with the help of smart phones.

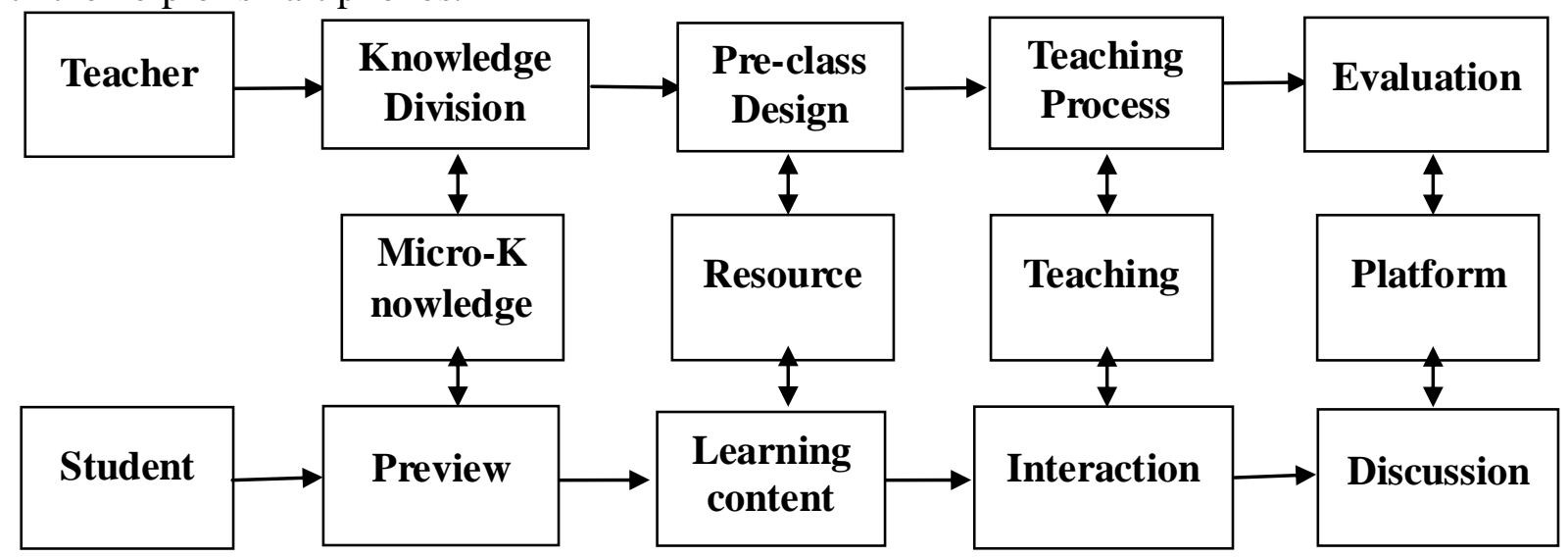

Figure 2. Data Structure by Micro Learning

At the stage of knowledge points, teachers mainly complete the transformation of curriculum resources, find logical relationship between the contents of micro-course, showing the most 
intuitive, the most concise, the most clear material to the students. In addition to displaying traditional texts, smart phones can also present modal images, audio and video by visual and audio way. These scenarios are conducive to enlightening the meaning of learning, attracting learners 'attention and making learners feel deepened and consolidated about content.

At the pre-class design stage, teachers will introduce key points which students need to learn through the E-mail, QQ, WeChat, so that students can preview the contents by using the smart phones according to the learning points. After that they can ensure learning tasks and arouse their interest.

According to its abstract and dynamic characteristics of data structure course, teachers adopts many teaching methods and multimedia technologies, so that each student is involved in teaching process. Teachers can use graphical algorithm demonstration to show the whole process dynamically in front of the students. It will not only stimulate student interest in learning, but also help students understand and remember knowledge, at the same time stimulate students' positive thinking, exert their learning initiative and promote innovative thinking.

At after-class discussion stage, teachers and students can through the interaction discuss knowledge and moderate learning evaluation. In the traditional classes, students mainly have passive learning. When they use mobile phones for micro-learning, students can interact and learn through micro-channel, Weibo, QQ, SMS, email, forum and other platforms to improve their participation. Teachers can understand the needs of all students. Each student can also communicate with all other students so as to solve the learning problems and help each other to learn more. Teachers can also track the interaction records, evaluate students' learning attitude and learning effect.

\section{Conclusion}

With the rapid development of computer technology and communication technology, digital, mobile and micro-miniaturized learning methods are developing rapidly and are gradually becoming a hot spot in the field of scientific research. As a new teaching mode, micro-learning is a useful complement to teaching process. Micro-learning extends the learning process to people's internet life space, making learning become a real part of life and greatly satisfying people's demand for learning. It has embodies the characteristics of fragmentation, autonomy, individualization and generalization, It also an inevitable result of the combination of educational philosophy and development of science and technology. In this paper, due to abstractdata structure courseandcomplicated algorithms, I propose a micro-learning mode based on smart phones. As educational theories of Micro Learning and the application of Micro Learning methods continue to be enriched, Micro Learning will surely become an effective way for learning by human beings.

\section{Acknowledgements}

Educational Scientific Planning Project of Shaanxi Province (Project Number: SGH17H479)

\section{References}

[1] Bruck P A.What is microlearning and why care about it[C]//Proceedings of Microlearning Conference 2006. Innsbruck: Innsbruck University Press, 2006: 24-28.

[2] Lindner M, Bruck P. A. Micromedia and cooperate learning [A]. Proceedings of the 3rd International Microlearning Conference [C].Australia, Innsbruck: Innsbruck University Press, 2007. 8.

[3] Hug T. Micro learning and narration: Exploring possibilities ofutilization of narrations and storytelling for the designing of micro units and didactical microlearning arrangements [A]. Proceedings of the fourth media transition conference [C]. USA, MIT: Cambridge (MA), 2005.1-14.

[4] Zhang Zhenhong, Yang Qinying, Han Zhi. A Study of Micro Learning: Present and Future[J]. 
China Educational Technology, 2013(11)

[5] Zhang Chunchao. Research on mobile micro learning of non English majors in Higher Vocational Colleges under the network environment [J]. Journal of Heihe University, 2017 (3).

[6] Wu Jinhong, ZhouLai. The application of micro learning in undergraduate teaching in Colleges and universities [J]. computer education, 2014 (9).

[7] Zhang Lina. Research on the application of micro learning based on smart phone in college students group [J]. Jingchu Academic, 2016 (6).

[8] Li Jing, Ji Weining. Microlearning era of postgraduate English Teaching of higher agricultural education [J]., 2016 (5).

[9] Hao Lianke, Tang Giping. "Research on the construction of learning platform of WeChat Internet plus education background,[J]. information science 2016 (8).

[10]Wang Cuiying, Song Weixi.Based on Andriod English mobile learning client design [J]. Automation and instrumentation, 2017 (3). 